\title{
Genomic Selection Outperforms
} Marker Assisted Selection for Grain Yield and Physiological Traits in a Maize Doubled Haploid Population Across Water Treatments

\section{OPEN ACCESS}

Edited by:

Laurent Gentzbittel,

National Polytechnic Institute of

Toulouse, France

Reviewed by:

Arvind Kumar,

International Rice Research Institute,

Philippines

Ajay Kohli,

International Rice Research Institute,

Philippines

*Correspondence:

Samuel Trachsel

trachselsam@gmail.com

Xuecai Zhang

xc.zhang@cgiar.org

${ }^{\dagger}$ Present Address:

Raman Babu,

DowDupont, Hyderabad, India

Samuel Trachsel,

KWS Group, Einbeck, Germany

\footnotetext{
Specialty section

This article was submitted to

Plant Breeding,

a section of the journal

Frontiers in Plant Science
}

Received: 01 August 2017 Accepted: 05 March 2018

Published: 20 March 2018

Citation:

Cerrudo D, Cao S, Yuan Y, Martinez C

Suarez EA, Babu $R$, Zhang $X$ and Trachsel S (2018) Genomic Selection

Outperforms Marker Assisted

Selection for Grain Yield and

Physiological Traits in a Maize Doubled

Haploid Population Across Water

Treatments. Front. Plant Sci. 9:366.

doi: 10.3389/fpls.2018.00366

\author{
Diego Cerrudo ${ }^{1,2}$, Shiliang Cao ${ }^{2,3}$, Yibing Yuan 2,4, Carlos Martinez ${ }^{2}$, \\ Edgar Antonio Suarez ${ }^{2}$, Raman Babu ${ }^{2 \dagger}$, Xuecai Zhang ${ }^{2 *}$ and Samuel Trachsel ${ }^{2 * t}$
}

${ }^{1}$ Facultad de Agronomia, Universidad Nacional de Mar del Plata, Buenos Aires, Argentina, ${ }^{2}$ Global Maize Program-Physiology, International Maize and Wheat Improvement Center (CIMMYT), Carretera México Veracruz, Texcoco, Mexico, ${ }^{3}$ Maize Research Institute, Heilongjiang Academy of Agricultural Sciences, Harbin, China, ${ }^{4}$ Maize Research Institute, Sichuan Agricultural University, Wenjiang, China

To increase genetic gain for tolerance to drought, we aimed to identify environmentally stable QTL in per se and testcross combination under well-watered (WW) and drought stressed (DS) conditions and evaluate the possible deployment of QTL using marker assisted and/or genomic selection (QTL/GS-MAS). A total of 169 doubled haploid lines derived from the cross between CML495 and LPSC7F64 and 190 testcrosses (tester CML494) were evaluated in a total of 11 treatment-by-population combinations under WW and DS conditions. In response to DS, grain yield (GY) and plant height (PHT) were reduced while time to anthesis and the anthesis silking interval (ASI) increased for both lines and hybrids. Forty-eight QTL were detected for a total of nine traits. The allele derived from CML495 generally increased trait values for anthesis, ASI, PHT, the normalized difference vegetative index (NDVI) and the green leaf area duration (GLAD; a composite trait of NDVI, PHT and senescence) while it reduced trait values for leaf rolling and senescence. The LOD scores for all detected QTL ranged from 2.0 to 7.2 explaining 4.4 to $19.4 \%$ of the observed phenotypic variance with $R^{2}$ ranging from 0 (GY, DS, lines) to $37.3 \%$ (PHT, WW, lines). Prediction accuracy of the model used for genomic selection was generally higher than phenotypic variance explained by the sum of QTL for individual traits indicative of the polygenic control of traits evaluated here. We therefore propose to use QTL-MAS in forward breeding to enrich the allelic frequency for a few desired traits with strong additive QTL in early selection cycles while GS-MAS could be used in more mature breeding programs to additionally capture alleles with smaller additive effects.

Keywords: genomic selection, maize, drought, QTL, DH

\section{INTRODUCTION}

Agriculture faces the challenge of increasing grain yield of major crops under climate scenarios with higher temperatures and more erratic precipitations as a result of anticipated climate change (Lobell et al., 2011). Climate change will have the strongest detrimental effects on crop production in tropical and subtropical environments since climate change is expected to have larger negative 
impact than in most other environments (Porter et al., 2014; Rosenzweig et al., 2014). Drought affects approximately $20 \%$ of the tropical and subtropical maize produced in developing countries in any given year (Heisey and Edmeades, 1999). Moreover, frequency and intensity of drought are projected to increase in the next decades ( $\mathrm{Li}$ et al., 2009). Rates of genetic gain are below the ones needed to meet the projected demand in the next few decades in many countries in SubSaharan Africa, Central America and Asia (Ray et al., 2013). Under drought, genetic gain is limited by large genotype-byenvironment interaction and the complexity of the genetic basis of drought tolerance (Bartels and Sunkar, 2005; Trachsel et al., 2016). Development of maize tolerant to drought that also performs well in non-stressed conditions is essential to ensure food security in the future (Pennisi, 2008).

In the past, secondary traits with strong genetic correlation with grain yield, high heritability, and cost-effective to measure have facilitated the selection in tropical breeding programs (Chapman and Edmeades, 1999; Betrán et al., 2003). Examples include anthesis silking interval (ASI), ears per plant, time to anthesis, leaf rolling, PHT, and senescence (Edmeades et al., 1999; Monneveux et al., 2006). More recently, NDVI measured during canopy development stages, as an indicator for early vigor was proposed as a secondary trait to be included in breeding for maize grain yield under both WW and DS conditions (Trachsel et al., 2016).

Traditional marker-assisted selection using QTL-MAS has been another complementary tool to speed up and make selection more efficient in maize breeding programs (Ribaut and Ragot, 2007; Tuberosa and Salvi, 2009; Beyene et al., 2016). Moreover, several QTL have been identified for grain yield under WW conditions (Messmer et al., 2009, 2011) and drought stressed conditions (Hao et al., 2010; Almeida et al., 2013), for PHT and NDVI (Trachsel et al., 2016), stay green (Almeida et al., 2013) and root traits (Trachsel et al., 2009). However, identification of QTL that are constitutive across environments and populations is essential for use in marker-assisted selection (Bernier et al., 2008). As a result of genotype-by-environment interaction, genetic correlation among traits and QTL detected usually differ among environments (Bolanos and Edmeades, 1996; Tuberosa et al., 2002). Moreover, QTL detected for a trait usually differ among genetic background (Rong et al., 2007) and between inbred line per se and their testcross hybrids (Mei et al., 2005; Szalma et al., 2007).

Many QTL studies carried out in the past have limited value for breeding because marker densities and genetic resolution were too low. Recently, however, genotyping-by-sequencing (GBS) has been proposed as an approach to increase the availability of molecular markers from $\sim 100$ to thousands of SNP evenly distributed throughout the genome (Elshire et al., 2011; Poland et al., 2012). Thus, the confidence interval surrounding a QTL was reduced, allowing the development of genetic maps with high resolution and precise mapping of QTL.

Marker-assisted selection based on genomic selection (GSMAS) was highlighted as a new approach for maize breeding (Meuwissen et al., 2001). In GS-MAS, favorable individuals are selected based on genomic estimated breeding values (GEBVs).
The major advantage of GS-MAS is that alleles with minor effects can be captured and used in selection (Meuwissen et al., 2001). Both QTL-MAS and GS-MAS require a high marker density in the discovery or training phase, respectively. In the deployment phase QTL-MAS only requires the use of markers flanking the target QTL (more for backcrosses with selection against the genome of the donor outside the area of the target QTL), while GS-MAS requires a higher number of markers adequately covering the entire genome resulting in higher genotyping cost for GS-MAS (Peng et al., 2014).

Simulation and empirical studies indicate that GS-MAS outperforms QTL-MAS for complex traits controlled by many QTL with minor effects or low heritability (Bernardo and Yu, 2007; Mayor and Bernardo, 2009; Heffner et al., 2010; Guo et al., 2013). If adequately integrated in the breeding workflow GS-MAS can partially replace field testing and reduce line development time (Heffner et al., 2010), while QTL-MAS can be used to introgress favorable alleles into an elite background and for integration of (native) traits into a breeding pipeline (Lorenzana and Bernardo, 2009; Zhao et al., 2012; Peng et al., 2014).

A combination of QTL-MAS and GS-MAS has also been suggested as an integration of knowledge on functional markers as either known causative mutations or known QTL associations with yet to be identified genes, for improved prediction (Zhao et al., 2012; Jonas and De Koning, 2016; Cao et al., 2017). These propositions suggest the importance of flexible GS as a method for introduction into breeding programs and combining it with QTL-MAS (Nakaya and Isobe, 2012). For both QTL-MAS and GS-MAS the success depends on excellent phenotypic characterization during the discovery or training phase, respectively.

In an aim to better understand the genetic architecture of drought tolerance and to evaluate the suitability of QTLor GS-MAS for selection toward drought tolerance, we used genotyping-by-sequencing technology to detect QTL and to develop GS models for grain yield and secondary traits in a $\mathrm{DH}$ population in per se and testcross evaluations, under WW and DS conditions. The specific objectives of this study were to: (i) evaluate QTL consistency across per se and testcross evaluations under WW and DS conditions, and detect QTL that are constitutive across studies with related populations; (ii) compare how QTL mapping and GS are affected by population (line per se vs. testcrosses) and treatments (WW vs. DS) and strategize their deployment in a drought breeding program.

\section{MATERIALS AND METHODS}

\section{Plant Material}

A bi-parental DH line population, consisting of 169 genotypes and the testcross hybrids, consisting of 190 genotypes was evaluated. The DH population was derived from an F1 cross between drought tolerant lines, La Posta Sequia C7-F64-2-62-1-B-B (LPSC7F64), and an elite inbred line from CIMMYT, CML495 (Cairns et al., 2013). The first parental line is traced to the La Posta Sequia Population (LPS), a white dent, Tuxpeñorelated synthetic, well adapted to lowland tropics. Full sib 
recurrent selection was carried out under drought conditions from cycle 0 to cycle 7 . The second parental line is a white flint line described as late-lowland with tolerance to rust, helminthosporium, good standability, belonging to heterotic group A. The lines were testcrossed to CML494 for the phenotypic evaluation.

\section{Experimental Design and Environmental Conditions}

Each of the populations (i.e., hybrids and lines) was evaluated under well-watered (WW) and drought stressed (DS) conditions in experiments conducted in different locations in Mexico during winter cycles of 2013, 2014, and 2016 (Table 1). A total of 11 experiments were conducted in Iguala (Guerrero, Mexico; IG), Agua Fria (Puebla, Mexico; AF) and Tlatizapan (Morelos, Mexico; TL); three for hybrids-WW (IG2013, AF2016, TL2016), four for hybrids-DS (IG2013, TL2013, TL2014, TL2016), two for lines-WW (IG2013, TL2013) and two for lines-DS (IG2013, TL2013).

For all the experiments, the design was an alpha-lattice $(0,1)$ replicated twice with incomplete blocks size of 5 . Plots consisted of one row $4.5 \mathrm{~m}$ long at row spacing of $0.75 \mathrm{~m}$. Plots were handseeded with two seeds per hill and thinned to one plant per hill (22 plants per plot; 6.6 plants $/ \mathrm{m}^{2}$ ) three weeks after planting.

For the DS treatment, water deficit was induced by withholding irrigation $12-15$ days ( $\sim 190$ GDD) before flowering with the aim of reaching the permanent wilting point at flowering at $40 \mathrm{~cm}$ soil depth. In the case of severe drought, as indicated by an ASI above $5 \mathrm{~d}$ on trial average, irrigation was applied $7 \mathrm{~d}$ after completion of anthesis, while a second irrigation was applied 3 wk after completion of anthesis. In the case of moderate DS, only one irrigation was applied during the grain filling period, 2 wk after completion of anthesis. For the WW experiments, evapotranspirated water was fully compensated for through weekly irrigations. Soil moisture content was measured at 10, 20, 30, 40, 60, and $100 \mathrm{~cm}$ soil depth three times weekly using Delta-t PR2/6 soil moisture probes (Delta-T devices, Cambridge, United Kingdom) to schedule irrigations in the drought stress treatment. Fertilization, insecticides and herbicides were applied as needed. Fertilizer quantities applied at each location are reported in Table $\mathbf{1 .}$

\section{Phenotypic Data Acquisition}

Several phenotypic traits were measured in each plot throughout the growing season. Two, four, five, and six weeks after planting the NDVI was measured using an RT-505 Greenseeker (Trimble, Ukia, CA, USA). NDVI measurements were taken by running the sensor in the middle of each plot at a height of $80 \mathrm{~cm}$ above the canopy. NDVI was calculated per the following equation: $\mathrm{R}_{\mathrm{NIR}^{-}}$ $\mathrm{R}_{\mathrm{Red}} / \mathrm{R}_{\mathrm{NIR}}+\mathrm{R}_{\mathrm{Red}}$, where $\mathrm{R}_{\text {NIR }}$ is the reflectance of near infrared wavelength, and $R_{\text {Red }}$ is the reflectance of red wavelength. The NDVI illustrates the part of red wavelength which is absorbed by the plant. At flowering, anthesis and silking dates were recorded when $50 \%$ of plants within a plot were shedding pollen and growing silks, respectively. The ASI was calculated as the difference between female and male flowering dates. Two, four and six weeks after flowering senescence was measured visually using a scale ranging from 1 (no senescence) to 9 (complete senescence) to approximate stay green (Trachsel et al., 2016). Leaf rolling was measured visually at flowering, and one and two weeks after flowering using a scale ranging from 1 (unrolled, turgid) to 5 (rolled, onion leaf). For NDVI, leaf rolling and senescence, the area under the curve was calculated by integrating a polynomial function of second degree fitted to individual measurements taken before (for NDVI) or after flowering (for senescence and leaf rolling). In this study, a new secondary trait indicative of early vigor, senescence and overall green leaf area and duration (GLAD) is proposed and evaluated. GLAD was calculated as:

$$
\mathrm{GLAD}=(\mathrm{PHT} \times \mathrm{NDVI}) / \text { senescence }
$$

were PHT is plant height at flowering and NDVI and senescence are area under the curve of four NDVI readings and three senescence scores as described above. The area under the curve (AUC) for NDVI and senescence was calculated by integrating a polynomial function of second degree fitted to individual

TABLE 1 | Summary of experiments describing their location, season, population, treatment (well-watered, WW; and drought stressed conditions, DS), planting date (PD), seasonal precipitation, mean seasonal temperatures (T), fertilization rates and latitude, longitude and altitude above sea level (asl).

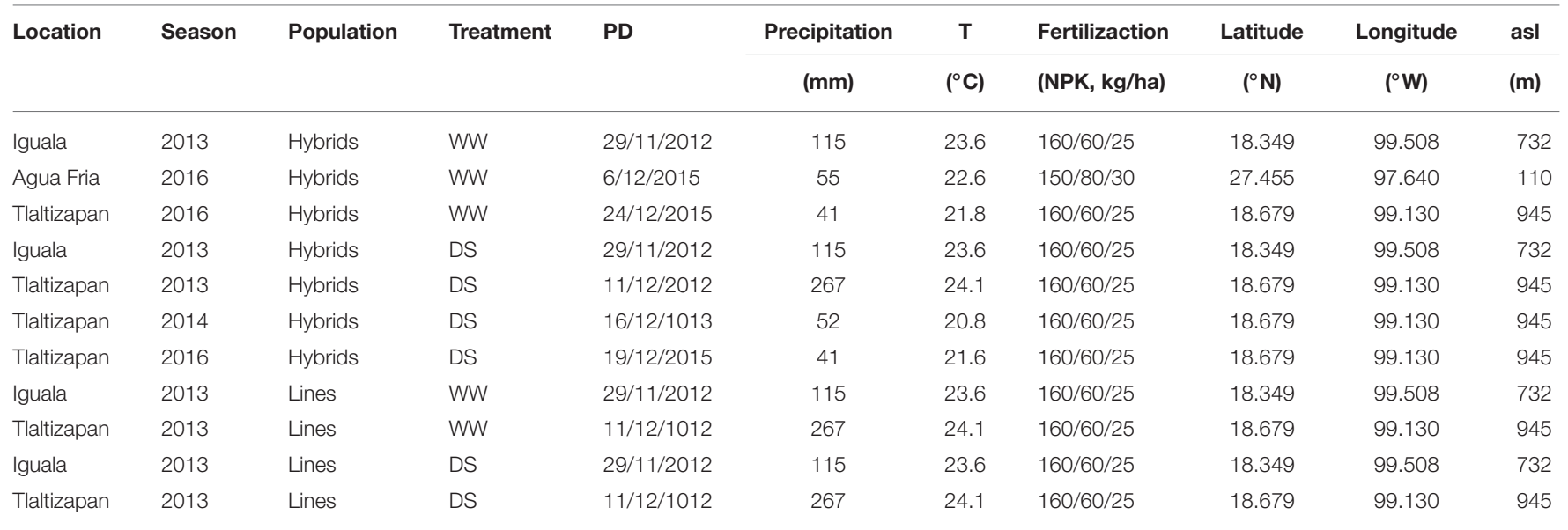


measurements taken before (for NDVI) or after flowering (for senescence).

After physiological maturity was reached, all ears of each plot were collected and shelled, grain moisture was recorded. Grain yield is reported at $12 \%$ moisture.

\section{Phenotypic Data Analysis}

The mixed effect linear model used for the analysis of phenotypic data measured in multilocation trials was:

$\mathrm{Y}_{\mathrm{hmlk}}=\mu+\alpha_{\mathrm{h}}+\mathrm{E}_{\mathrm{ml}}+\alpha_{\mathrm{hEml}}+\mathrm{r}_{\mathrm{m}}\left(\mathrm{E}_{\mathrm{ml}}\right)+\mathrm{r}_{\mathrm{m}}\left(\mathrm{E}_{\mathrm{ml}}\right) \delta_{\mathrm{k}}+\mathrm{e}_{\mathrm{hmlk}}$

Where $Y_{h m l k}$ is the trait value of the $h_{\text {th }}$ genotype $(h=190$ and 169 for hybrids and lines, respectively) for the $l_{\text {th }}$ location (hybrids-WW: $1=3$; hybrids-DS: $1=4$, lines-WW: $\mathrm{I}=2$; linesDS: $I=2)$, the $m_{t h}$ replication $(m=2) ; \mu$ the overall mean, $\alpha_{\mathrm{h}}$ the main effect of the genotype, $\mathrm{E}_{\mathrm{ml}}$ the effect of the location, $\alpha_{\mathrm{hEml}}$ the genotype-by-location interaction, $\mathrm{r}_{\mathrm{m}}\left(\mathrm{E}_{\mathrm{ml}}\right)$ the replication within location effect and $r_{m}\left(E_{m l}\right) \delta_{k}$ the effect of blocks within replicates within locations and the random error term $\mathrm{e}_{\mathrm{hmlk}}$. All factors except $\mu$ were set as random. Best linear unbiased predictors (BLUPs) of genotypes, variance components, and broad sense heritability were obtained. Data for each populationby-treatment combination were analyzed separately. Analysis of the genotype-by-treatment (i.e., WW and DS) interactions was carried out separately for hybrids and lines. For that, terms for treatment and genotype-by-treatment interaction were added to the model described before. Location, genotype and treatment were set as fixed and the rest as random factors. Plant stand was used as a covariate for grain yield and NDVI calculations. Plots with less than 18 plants were removed from the analysis. Variance components were estimated by restricted maximum likelihood (REML) and heritability as the relationship between genetic and phenotypic variance, according to the formula:

$$
h^{2}=\left(\sigma_{\mathrm{G}}^{2}\right) /\left(\left(\sigma_{\mathrm{G}}^{2}+\left(\sigma_{\mathrm{GxE}}^{2} / l\right)+e /\left(r^{*} l\right)\right)\right.
$$

where $\sigma_{G}^{2}$ is the genotypic variance, $\sigma_{\mathrm{GxE}}{ }^{2}$ the genotype-byenvironment interaction variance, e the error term, 1 the number of environments and $r$ the number of replications within environments.

BLUPs for genotypes effects are shrinkage predictors obtained as:

$$
\tilde{\alpha}=\mathrm{G}^{\wedge} \mathrm{Z}^{\wedge}-1(y-1 \mu)
$$

using matrix notation, where $y$ is the vector of the response variable, $\mathrm{G}^{\wedge}$ the matrix of variance covariance of the random effects, $Z$ the design matrix for random effects in the model, $\mathrm{V}^{\wedge}$ estimated variance of $\mathrm{y}, 1$ a vector of ones and $\mu$ the overall mean, the only fixed parameter in the model. The cor.test function in $\mathrm{R}$ was used to calculate correlations among BLUPs. Genetic correlations among traits were estimated with a method described previously (Cooper and Delacy, 1994).

Genotyping and Linkage Map Construction For all the maize lines tested in this study, leaf samples bulked from 12 plants of each line were used for DNA extraction with a Cetyltrimethylammonimum bromide (CTAB) procedure (CIMMYT, 2005). A genotyping-by-sequencing (GBS) protocol commonly used by the maize research community was applied at the Cornell University Biotechnology Resource Center in this study (Elshire et al., 2011; Wu et al., 2016). Briefly, the GBS libraries were constructed in 96-plex, and genomic DNA was digested with the restriction enzyme ApeK1. Each library was sequenced on a single lane of Illumina flow cell. SNP calling was performed using TASSEL 5.0 GBS Discovery Pipeline with B73 as the reference genome. Initially, 955,690 SNPs evenly distributed on maize chromosomes were called for each line; 955,120 of them were assigned to chromosomes 1-10, and 570 of them could not be anchored to any of the 10 maize chromosomes. A bin map was constructed by using 20,473 high quality filtered GBS SNPs, details on how to construct the linkage map were described previously (Cao et al., 2017). In brief, neighbor SNPs having high similarity haplotype information were clustered into one bin, and each bin was treated as single marker to construct the genetic map. The following steps were performed to reduce genotyping error and eliminate the low quality SNPs from the bin map: (1) $\mathrm{DH}$ lines with heterozygosity rate greater than $5 \%$ and/or missing rate greater than $20 \%$ were eliminated from further analysis; (2) unlinked SNPs were removed from further analysis, where the window size was 8 , similarity rates of all the SNPs within each window were calculated to remove the unlinked SNPs, threshold of similarity rate was 95\%; (3) the consecutive SNPs with high similarity rate, i.e., 95\%, were merged into one bin; and (4) bins were treated as genetic markers to construct a genetic map. The genetic map was constructed with 191 bins in software QTL IciMapping Version 4.0 (www.isbreeding.net; Wang et al., 2014). The total genetic map length was $987.35 \mathrm{cM}$ resulting in an average distance between markers of $5.15 \mathrm{cM}$.

\section{Genomic Selection Analysis}

Genomic prediction was implemented in rrBLUP package (Endelman, 2011) in DH population. SNPs in the genetic map were used for genomic prediction. Details of the implementation of rrBLUP were described earlier (Zhao et al., 2012). A fivefold cross-validation scheme with 100 replications was used to generate the training and validation sets and assess the prediction accuracy. The average value of the correlations between the phenotype and the genomic estimated breeding values was defined as genomic prediction accuracy $\left(\mathrm{r}_{\mathrm{MG}}\right)$.

\section{RESULTS}

\section{Heritability, Phenotypic Data and Correlations Between Grain Yield and Secondary Traits}

A population of $\mathrm{DH}$ lines was evaluated per se and in testcross combination under WW and DS conditions. Significant genotype-by-location interaction was detected when experiments were combined by population and irrigation treatment (i.e., hybrids-WW and hybrids-DS; lines-WW and lines-DS) for all traits, with exception of PHT for lines under DS (Table 2). For most traits, heritability of the combined analysis remained 
TABLE 2 | Mean, 1st and 3rd quartile, heritability, genotype effect and genotype-by-location interaction ( $\left.\mathrm{g}^{*} \mathrm{l}\right)$, for different traits evaluated in experiments that included hybrids under well-watered (Hybrids_WW), hybrids under drought stress (Hybrids_DS), lines under well-watered (Lines_WW) and lines under drought stress conditions (Lines_DS).

\begin{tabular}{|c|c|c|c|c|c|c|c|c|c|c|}
\hline \multirow[t]{2}{*}{ Experiment } & & \multicolumn{9}{|c|}{ Trait } \\
\hline & & $\begin{array}{c}\text { GY } \\
\text { (t/ha) }\end{array}$ & $\begin{array}{c}\text { AD } \\
\text { (days) }\end{array}$ & $\begin{array}{l}\text { PHT } \\
(\mathrm{cm})\end{array}$ & $\begin{array}{c}\text { ASI } \\
\text { (days) }\end{array}$ & NDVI & SEN & LR & GLAD & $\begin{array}{l}\text { DSS } \\
(\%)\end{array}$ \\
\hline \multirow[t]{7}{*}{ Hybrids_WW } & Mean & 7.02 & 81.8 & 221 & -0.11 & 15.9 & & & & 63.0 \\
\hline & SE & 0.65 & 1.43 & 7.2 & 1.26 & 0.99 & & & & $N A$ \\
\hline & 1st quartile & 6.71 & 81.2 & 218 & -0.29 & 15.7 & & & & 61.3 \\
\hline & 3rd quartile & 7.39 & 82.4 & 225 & 0.04 & 16.1 & & & & 64.8 \\
\hline & $h^{2}$ & 0.70 & 0.78 & 0.75 & 0.52 & 0.51 & & & & \\
\hline & genotype & $\star \star \star *$ & 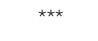 & $\star \star \star *$ & $\star * \star$ & $* \star *$ & & & & \\
\hline & $g^{\star} \mid$ & 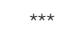 & $\star \star \star *$ & 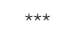 & $\star \star \star *$ & $\star \star \star \star ~$ & & & & \\
\hline \multirow[t]{7}{*}{ Hybrids_DS } & Mean & 2.59 & 83.1 & 195 & 1.83 & 14.1 & 127 & 52.9 & 22.6 & \\
\hline & SE & 0.38 & 0.87 & 0.35 & 0.86 & 0.71 & 6.9 & 4.96 & 1.67 & \\
\hline & 1st quartile & 2.51 & 82.7 & 194 & 1.78 & 13.9 & 126 & 52.5 & 22.3 & \\
\hline & 3rd quartile & 2.68 & 83.5 & 196 & 1.88 & 14.3 & 128 & 53.1 & 23.0 & \\
\hline & $h^{2}$ & 0.37 & 0.65 & 0.31 & 0.17 & 0.57 & 0.38 & 0.14 & 0.53 & \\
\hline & genotype & $\star \star$ & $\star \star$ & $\star \star$ & * & $\star \star$ & $\star \star \star$ & ns & $\star \star \star$ & \\
\hline & $g^{\star} \mid$ & $\star \star \star$ & $\star \star \star$ & 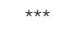 & 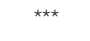 & $\star \star \star$ & $\star \star \star$ & ** & $\star \star \star$ & \\
\hline \multirow[t]{7}{*}{ Lines_WW } & Mean & 2.07 & 87.4 & 112 & 0.61 & 11.6 & & & & 63.8 \\
\hline & SE & 0.28 & $N A$ & 8.2 & 2.59 & 0.69 & & & & $N A$ \\
\hline & 1st quartile & 1.89 & 86.3 & 107 & 0.38 & 11.4 & & & & 60.2 \\
\hline & 3rd quartile & 2.25 & 88.5 & 117 & 0.82 & 11.7 & & & & 68.7 \\
\hline & $h^{2}$ & 0.52 & 0.79 & 0.81 & 0.30 & 0.45 & & & & \\
\hline & genotype & $\star \star \star *$ & 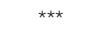 & 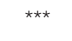 & * & $\star \star \star *$ & & & & \\
\hline & $g^{\star} \mid$ & 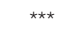 & 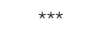 & 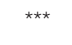 & 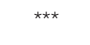 & 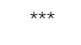 & & & & \\
\hline \multirow[t]{7}{*}{ Lines_DS } & Mean & 0.75 & 89.6 & 102 & 1.07 & 10.9 & 142 & 69.0 & 8.14 & \\
\hline & SE & 0.21 & 1.5 & 7.49 & 1.42 & 0.18 & 11.2 & 5.56 & 0.26 & \\
\hline & 1st quartile & 0.63 & 88.0 & 98.5 & 1.81 & 10.6 & 139 & 66.3 & 7.46 & \\
\hline & 3rd quartile & 0.85 & 91.3 & 106 & 0.20 & 11.3 & 145 & 71.4 & 8.65 & \\
\hline & $h^{2}$ & 0.76 & 0.91 & 0.80 & 0.76 & 0.71 & 0.61 & 0.66 & 0.81 & \\
\hline & genotype & $\star \star \star \star$ & 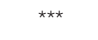 & $\star \star \star *$ & $\star \star * *$ & $* * *$ & 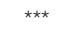 & $* \star *$ & 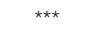 & \\
\hline & $g^{\star} \mid$ & 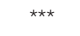 & $\star \star \star$ & ns & * & $\star \star$ & 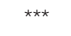 & 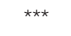 & $\star \star \star \star$ & \\
\hline
\end{tabular}

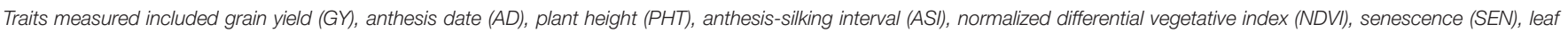
rolling (LR), GLAD and drought stress susceptibility (DSS).

$n s,{ }^{*},{ }^{\star \star},{ }^{* \star \star}$ non-significant, and significant at $p<0.1,0.05$, and 0.01 , respectively.

acceptably high. Heritability of PHT and anthesis were the highest in most experiments, with values above 0.75. The ASI had the lowest values, ranging from 0.17 to 0.76 . Under DS conditions, grain yield, NDVI and GLAD had the highest heritability values, ranging from 0.45 to 0.81 . Meanwhile, senescence and leaf rolling had the lowest heritability, ranging from 0.14 to 0.66 .

Grain yield for lines and hybrids was on average reduced by $63 \%$ under DS relative to WW (Table 2). Drought stress equally increased ASI (1.94 and 0.38 days for hybrids and lines, respectively), decreased PHT (26 and $10 \mathrm{~cm}$ for hybrids and lines, respectively) and delayed anthesis (1.8 and 2.2 days for hybrids and lines, respectively). Differences in NDVI between WW and DS before the onset of drought, can be explained by differences in environments as a result of unbalanced experimental data. Drought trials were all carried out in the winterseason (with lower temperatures compared to the summerseason), while the non-stressed trials were grown in both the summer and winterseason. Since the crop typically develops slower in winter and NDVI readings were taken in calendar days after planting, plants were on average less developed in Winter, relative to plants grown in trials carried out in both summer and winter, resulting in lower NDVI values.

DS were measured at completely dry locations ( 900-1,100 masl) whereas additional WW treatments were included in locations with higher precipitations.

Senescence, leaf rolling and GLAD were only recorded under DS conditions. Averaged across treatments, hybrids reached anthesis six days earlier, grew $101 \mathrm{~cm}$ taller and had 24\% higher NDVI than lines. Leaf rolling, and GLAD were 30 and $177 \%$ higher in the hybrids than in the lines and senescence was $11 \%$ 
higher for the lines. The ASI did not differ among lines and hybrids $(p>0.05)$.

Correlations among grain yield and secondary traits differed across populations and irrigation treatments (Table 3). Grain yield was moderately correlated to NDVI $\left(r_{\mathrm{g}}=0.84 ; r_{\mathrm{p}}=0.53\right)$ and GLAD $\left(r_{\mathrm{g}}=0.70 ; r_{\mathrm{p}}=0.49\right)$, for hybrids-WW and hybridsDS, respectively. Grain yield correlated moderately to weakly with PHT, with highest correlation coefficients $\left(r_{\mathrm{g}}=0.67 ; r_{\mathrm{p}}\right.$ $=0.54$ ) for hybrids-WW. Correlations with anthesis, ASI, leaf rolling and senescence were weak or even non-significant for some trait-by-treatment combinations.

\section{Detected QTL for Grain Yield and Secondary Traits; Collocation in Bins 1.02, 1.03 , and 7.04}

The analysis revealed a total of 48 significant QTL for nine traits evaluated (Table 4). They included 13 QTL detected in hybridsWW, 12 in hybrids-DS, 12 in lines-WW and nine in lines-DS. Thirteen QTL were detected for PHT, eight for grain yield, seven for anthesis, six for senescence, four for ASI, three for GLAD and two each for leaf rolling, NDVI and DSS. In most cases, the allele derived from CML495 increased trait values for anthesis, ASI, PHT, NDVI, DSS, and GLAD, while it reduced trait values for DSS, leaf rolling and senescence. The LOD scores for all detected QTL ranged from 2.0 (grain yield, hybrids-DS) to 7.2 (grain yield, lines-WW) explaining 4.4 (grain yield, lines-WW) to $19.4 \%$ (grain yield, lines-WW) of the observed phenotypic variance. Only one constitutive QTL for grain yield was detected, which mapped to bin 8.08 for lines in WW and DS. The trait increasing allele was derived from LPSC7F64 in both cases. None

TABLE 3 | Phenotypic $\left(r_{p}\right)$ and genotypic $\left(r_{g}\right)$ correlations between grain yield and different secondary traits for lines per se and their testcross hybrids under well-watered (WW) and drought stressed (DS) conditions.

\begin{tabular}{|c|c|c|c|c|}
\hline \multirow[t]{2}{*}{ Trait } & \multicolumn{2}{|c|}{ Hybrids_WW } & \multicolumn{2}{|c|}{ Lines_WW } \\
\hline & $r_{p}$ & $\mathbf{r}_{\mathbf{g}}$ & $r_{p}$ & $\mathbf{r}_{\mathbf{g}}$ \\
\hline Anthesis & ns & ns & ns & ns \\
\hline PHT & $0.54^{\star \star \star}$ & $0.67^{\star \star \star}$ & $0.26^{\star \star \star}$ & $0.25^{\star \star \star}$ \\
\hline ASI & ns & $\mathrm{ns}$ & $-0.22^{\star \star \star}$ & $-0.66^{\star \star \star}$ \\
\hline \multirow[t]{2}{*}{ NDVI } & $0.53^{\star \star \star}$ & $0.84^{\star \star \star}$ & $0.53^{\star \star \star}$ & $0.70^{\star \star \star}$ \\
\hline & \multicolumn{2}{|c|}{ Hybrids_DS } & \multicolumn{2}{|c|}{ Lines_DS } \\
\hline Anthesis & $-0.20^{\star \star \star}$ & ns & $-0.18^{\star \star \star}$ & $-0.21^{\star * \star}$ \\
\hline PHT & $0.29^{\star \star \star}$ & $\mathrm{ns}$ & $0.36^{\star \star \star}$ & $0.38^{\star \star \star}$ \\
\hline ASI & $-0.27^{\star \star \star}$ & $\mathrm{ns}$ & $-0.14^{\star \star \star}$ & $-0.21^{\star \star \star}$ \\
\hline NDVI & $0.42^{\star \star \star}$ & $0.72^{\star \star \star}$ & $0.48^{\star \star \star}$ & $0.66^{\star \star \star}$ \\
\hline Senecence & $-0.11^{*}$ & $\mathrm{~ns}$ & $-0.32^{\star \star \star}$ & $-0.25^{\star \star \star}$ \\
\hline Leaf rolling & $-0.20^{\star \star \star}$ & ns & $-0.42^{\star \star \star}$ & $-0.52^{\star \star \star}$ \\
\hline GLAD & $0.49^{\star \star \star}$ & $0.70^{\star \star \star}$ & $0.60^{\star \star \star}$ & $0.61^{\text {***}}$ \\
\hline
\end{tabular}

Traits evaluated included anthesis, plant height (PHT), anthesis-silking interval (ASI), normalized differential vegetative index NDVI, senescence, leaf rolling and GLAD.

$n s,{ }^{*},{ }^{* \star},{ }^{* \star \star}$ Correlations non-significant, significant at $p<0.1,0.05$, and 0.01, respectively. of the 39 QTL detected for secondary traits overlapped for hybrid and line or across treatments.

A collocation of QTL for grain yield (hybrids-WW), anthesis (lines-DS), PHT (hybrids-WW), NDVI (hybrids-WW), and GLAD (hybrids-DS) was detected in bin 1.03 (Table 4). The phenotypic variance explained by each QTL ranged from 4.8 (GLAD, hybrids-DS) to $13.8 \%$ (NDVI, hybrids-WW). The allele derived from CML495 delayed anthesis by $1.07 \mathrm{~d}$, increased GLAD by 0.16 , grain yield by $0.18 \mathrm{t} / \mathrm{ha}$, NDVI by 0.13 and PHT by $2.89 \mathrm{~cm}$. Another collocation was identified in bin 1.02, where QTL for DSS (hybrids), anthesis (hybrids-DS), PHT (hybridsWW) and GLAD (hybrids-DS) were detected. The phenotypic variance explained by those QTL ranged from 4.7 (GLAD, hybrids-DS) to $10.9 \%$ (anthesis, hybrids-DS). The allele derived from CML495 delayed flowering by $0.26 \mathrm{~d}$, increased GLAD by 0.16 , PHT by $1.55 \mathrm{~cm}$ and DSS by $1.12 \%$. Another collocation of QTL for PHT (hybrids-WW), leaf rolling (hybrids-DS) and senescence (hybrids-DS) detected in bin 7.04 is indicative of a beneficial effect of early vigor when stress occurs during the post flowering period. The allele derived from CML495 increased PHT and decreased leaf rolling and senescence.

The positive effect of a short ASI on grain yield was confirmed by a collocation of repulsive QTL for ASI and grain yield in bin 4.08 (Table 4). A collocation of repulsive QTL for anthesis and grain yield in bin 4.10 is indicative of the contribution of this chromosomal region to drought escape by early flowering. The grain yield QTL in this bin had the largest phenotypic variance explained among all detected QTL in this study (19.4\%), with the trait increasing allele derived from LPSC7F64.

\section{$\mathbf{R}^{2}$ of QTL and Prediction Accuracy of GS Models for Grain Yield and Secondary Traits}

The variation $\left(\mathrm{R}^{2}\right)$ explained by all QTL for a single trait-byexperiment combination was moderate for grain yield $(25.1 \%$, lines-WW), PHT (37.3\%, lines-WW) and senescence $(25.2 \%$, lines-DS), indicating that genetic control was well captured and is potentially usable in QTL-MAS (Table 5). Lower $R^{2}$ values for the rest of the trait-by-experiment combinations indicate that traits are controlled by many minor effect QTL and genotypeby-environment interactions are high, which are not suitable for QTL-MAS. The prediction accuracy of GS models was larger than the $R^{2}$ values for grain yield and secondary traits, for hybrids and lines both under WW and DS conditions; except for grain yield and ASI in lines-WW and for leaf rolling in lines-DS. The advantages of the GS-MAS over the QTL-MAS approach were larger under DS than under WW conditions for grain yield, anthesis and PHT as indicated in differences between $R^{2}$ (QTL-MAS) and prediction accuracies (GS-MAS); for instance, prediction accuracy of GS and $R^{2}$ values for grain yield were 16.9 vs. 0 and 22.3 vs. 0 for hybrids-DS and lines-DS, respectively. Moreover, the prediction accuracy of grain yield under WW was better than under DS (23.5 and 19.6 for the average of hybrids and lines under WW and DS, respectively) and the prediction of most of the secondary traits were better than for GY except for lines-WW. A similar trend was also observed for the 
TABLE 4 | Summary of all QTL detected in experiments (Exp) of hybrids (HY) and lines (LI), under well-watered (WW) and drought stressed (DS) conditions showing chromosome (Chr), position (Pos), bin, flanking markers, LOD scores, phenotypic variance explained by a QTL (PVE), and additive effects.

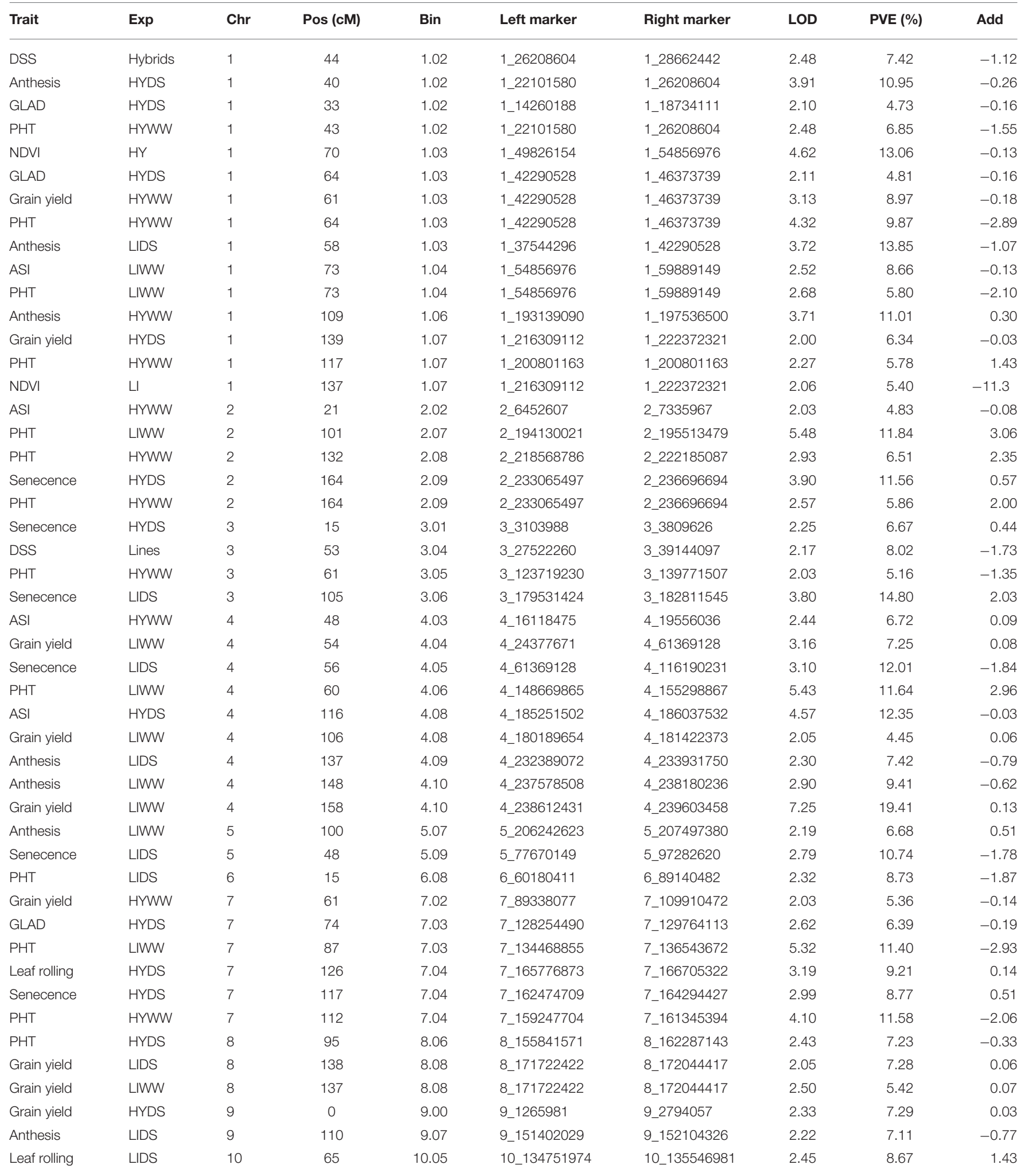

Traits include normalized differential vegetative index NDVI, anthesis, anthesis-silking interval (ASI), plant height (PHT), senescence, GLAD, grain yield, and drought stress susceptibility (DSS). 


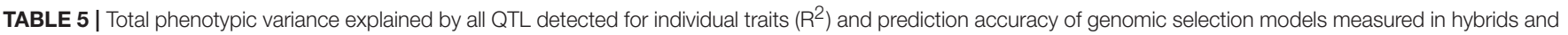
lines per se under well-watered (WW) and drought stressed (DS) conditions.

\begin{tabular}{|c|c|c|c|c|c|c|c|c|}
\hline \multirow[b]{2}{*}{ Trait } & \multicolumn{4}{|c|}{ Phenotypic var. explained by all QTL; $\mathbf{R}^{2}$} & \multicolumn{4}{|c|}{ GS prediction accuracy } \\
\hline & Hybrid_WW & Hybrid_DS & Line_WW & Line_DS & Hybrid_WW & Hybrid_DS & Line_WW & Line_DS \\
\hline GY & 8.59 & 0 & 25.1 & 0 & 21.5 & 16.9 & 25.5 & 22.3 \\
\hline DSS & 6.78 & NA & 0 & NA & 20.6 & NA & 0.25 & NA \\
\hline Anthesis & 10.4 & 9.57 & 9.1 & 11.8 & 30.3 & 38.3 & 25.2 & 48.9 \\
\hline PHT & 17 & 6.45 & 37.3 & 0 & 30.0 & 27.7 & 26.0 & 28.0 \\
\hline ASI & 0 & 12.4 & 7.7 & 0 & 19.5 & 44.9 & 25.3 & 40.6 \\
\hline NDVI & 12.2 & NA & 0 & NA & 16.0 & NA & 25.0 & NA \\
\hline SEN & NA & 14.4 & NA & 25.2 & NA & 31.4 & NA & 42.9 \\
\hline LR & NA & 8.59 & NA & 7.84 & NA & 18.7 & NA & -7.1 \\
\hline GLAD & NA & 7.07 & NA & 0 & NA & 32.3 & NA & 25.1 \\
\hline
\end{tabular}

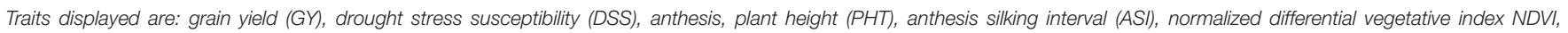
senescence (SEN), leaf rolling (LR) and GLAD.

secondary traits. A positive correlation was observed between the genomic prediction accuracy and trait heritability for hybridsWW $\left(R^{2}=0.83 ; p<0.02\right.$, Figure 1). For the other treatmentby-population combinations the correlation between genomic prediction accuracy and trait heritability was low.

\section{Hybrids With Best Yield Potential and Yield Stability}

The best ten hybrids for WW and DS conditions out-yielded the commercial check (DK357) and the trial mean by 12 and $13 \%$ under WW, and by 18 and $11 \%$ under DS conditions, respectively (Table 6). Although the genotype-by-water treatment interaction was significant (data not shown) three hybrids with outstanding yield potential and stability (i.e., good performance under WW and DS) were identified (Table 6). The hybrids (LPSC7F64/CML495)DH220/CML494, (LPSC7F64/CML495)DH290/CML494 and (LPSC7F64/ CML495)DH30/CML494, ranked 1st, 2nd, and 3rd under WW conditions, and 22nd, $18^{\text {th }}$, and 13 th, out of 190 under DS conditions, respectively. On average, the three hybrids with high yield potential and yield stability across environments out yielded the commercial check and the trial mean by 12 and $13 \%$ under WW and by 12 and 6\% under DS, respectively.

\section{DISCUSSION}

We created contrasting WW and DS conditions for the per se evaluation of $\mathrm{DH}$ lines and in testcross combination. The grain yield reduction of $63 \%$ under DS compared to WW conditions was similar to the ones reported for experiments following the same protocols, with a related hybrid population (Trachsel et al., 2016). Moderate to severe drought stress levels allowed us to detect QTL across experiments and treatments (i.e., hybridsWW, hybrids-DS, lines-WW and lines-DS) and to identify lines and hybrids with good performance across treatments.

Both PHT and NDVI were positively correlated with grain yield under WW and DS conditions, supporting their potential utility for indirect selection for improved grain yield under drought stress as suggested previously (Messmer et al., 2011;
Trachsel et al., 2016). GLAD had large positive correlations with grain yield both for lines and hybrids (only measured under DS conditions). GLAD integrates information on different morpho-physiological traits related to grain yield (i.e., early and general vigor and senescence) and could be used to identify genotypes that better combine those traits. Since neither PHT nor senescence were correlated with grain yield for hybrids, it is likely that the positive correlation was caused by large NDVI.

\section{Beneficial Effects of Early Vigor and Escape on Grain Yield Evidenced in Bins $1.02,1.03$, and 7.04}

A collocation of QTL for anthesis (hybrids-DS), PHT (hybridsWW), GLAD (hybrids-DS), and DSS (hybrids) is indicative of the importance of bin 1.02 for the genetic control of grain yield and early vigor. Detection of QTL for anthesis and for DSS in this region indicates that the physiological mechanism conveying grain yield under drought stressed conditions is drought escape achieved through an earlier flowering. The importance of this bin is further supported by collocations with QTL detected for anthesis (Salvi et al., 2011) and PHT (Schön et al., 1993) in other genetic backgrounds. Collocations of QTL were detected for PHT, NDVI and senescence, which are all components of GLAD, in the same bin (Trachsel et al., 2016). Two candidate genes potentially accounting for the detected QTL are ct2 (compact plant2) and $c f r 1$ (coupling factor reduction1). The first gene is involved in CLAVATA signaling, which controls shoot meristem size and shoot growth (Bommert et al., 2013), while cfrl affects chloroplast function and seedling vigor (Echt et al., 1987).

A collocation of QTL for anthesis (lines-DS), GLAD (hybridsDS), grain yield (hybrids-WW), PHT (hybrids-WW), and NDVI (hybrids-WW) was detected in bin 1.03, indicative of the importance of this bin for the genetic control of early and general vigor (i.e. NDVI and PHT) and grain yield. Candidate genes for the response related to this chromosome region are a set of genes related to chlorophyll fluorescence $(h c f 3, h c f 31, h c f 6)$ and leaf color $\left(p g^{*}-N 484 A, p g^{*}-N 484 B\right.$, and $\left.p g^{*}-N 526 C\right)$, which may relate to seedling vigor. 


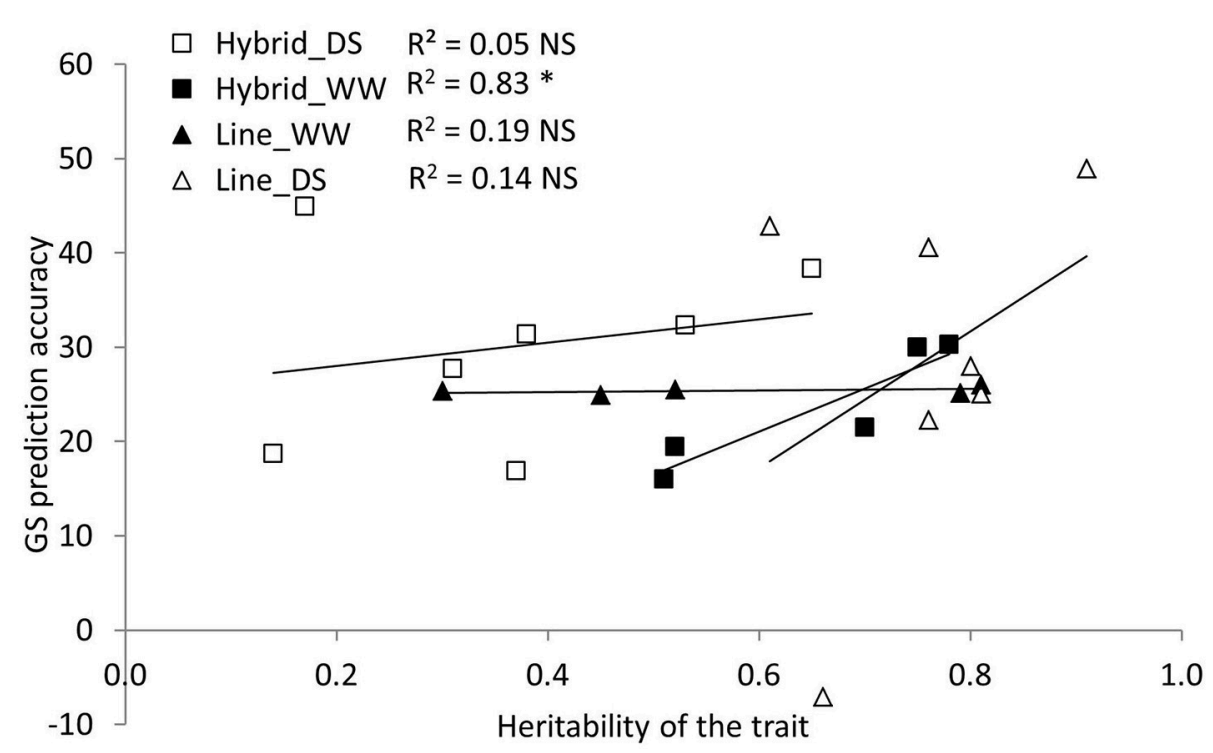

FIGURE 1 | Genomic selection prediction accuracy as a function of the heritability for different traits of maize hybrids under well-watered (Hybrids_WW), hybrids under drought stress (Hybrids_DS), lines under well-watered (Lines_WW) and lines under drought stress conditions (Lines_DS). Traits measured included grain yield, anthesis date, plant height, anthesis-silking interval, normalized differential vegetative index, senescence, leaf rolling, GLAD and drought stress susceptibility.

TABLE 6 | Grain yield (t/ha) for the top 10 performing hybrids, the local check (DK-357) and the mean of all evaluated hybrids, under well-watered (WW) and drought stressed (DS) conditions, and grain yield for three hybrids with best combination of potential and grain yield stability, also under well-watered and drought stressed conditions.

\begin{tabular}{|c|c|c|c|c|c|c|c|c|}
\hline \multicolumn{3}{|l|}{ Top 10 under WW } & \multicolumn{3}{|l|}{ Top 10 under DS } & \multicolumn{3}{|c|}{ Best for potential-stability combination } \\
\hline (LPSC7F64/CML495)DH265/CML494 & 8.20 & 2.51 & (LPSC7F64/CML495)DH56/CML494 & 2.93 & 6.9 & (LPSC7F64/CML495)DH290/CML494 & 7.99 & 2.76 \\
\hline (LPSC7F64/CML495)DH290/CML494 & 7.99 & 2.76 & (LPSC7F64/CML495)DH40/CML494 & 2.93 & 7.3 & (LPSC7F64/CML495)DH30/CML494 & 7.85 & 2.79 \\
\hline (LPSC7F64/CML495)DH13/CML494 & 7.91 & 2.73 & (LPSC7F64/CML495)DH95/CML494 & 2.91 & 7.4 & & & \\
\hline (LPSC7F64/CML495)DH15/CML494 & 7.85 & 2.62 & (LPSC7F64/CML495)DH257/CML494 & 2.86 & 7.4 & & & \\
\hline (LPSC7F64/CML495)DH241/CML494 & 7.85 & 2.73 & (LPSC7F64/CML495)DH119/CML494 & 2.82 & 7.1 & & & \\
\hline (LPSC7F64/CML495)DH30/CML494 & 7.85 & 2.79 & (LPSC7F64/CML495)DH30/CML494 & 2.82 & 7.4 & & & \\
\hline (LPSC7F64/CML495)DH11/CML494 & 7.84 & 2.68 & (LPSC7F64/CML495)DH127/CML494 & 2.82 & 7.0 & & & \\
\hline (LPSC7F64/CML495)DH9/CML494 & 7.83 & 2.56 & (LPSC7F64/CML495)DH282/CML494 & 2.80 & 7.5 & & & \\
\hline Top 10 mean & 7.96 & 2.67 & & 2.87 & 7.28 & & & \\
\hline
\end{tabular}

A collocation of QTL for PHT (hybrids-WW), leaf rolling (hybrids-DS) and senescence (hybrids-DS) detected in bin 7.04 may suggests that general vigor confers stress avoidance later in the season, since the QTL for PHT was in repulsion with the QTL for leaf rolling and senescence. While PHT reflects general shoot vigor, it may also indicate root vigor (Richner et al., 1996; Hammer et al., 2009; Grieder et al., 2013) as a result of allometric root-shoot relations. Shoot vigor indicative of a vigorous root system, would indirectly allow for greater water and nutrient uptake from deeper soil layers resulting in lower stress levels and reduced leaf rolling and senescence under drought stress. This hypothesis is supported by QTL previously detected for PHT
(Sibov et al., 2003) and root architecture in this bin (Tuberosa et al., 2003; Trachsel et al., 2009; Cai et al., 2012). Potential candidate genes underlying the observed response are $h c f 101$, $h c f 103$, and $h c f 104$, which are related to chlorophyll fluorescence conveying sufficient assimilates and plant vigor.

\section{Detection of QTL Constitutive Across Environments or Consistent Across Populations}

Although a total of 48 QTL were detected for grain yield and secondary traits, none of them was consistently detected 
in hybrids and lines as a result of the low correlation found among lines and hybrids and across treatments as a result of genotype-by-environment interaction, epistasis and heterosis (Mei et al., 2005; Mihaljevic et al., 2005; Szalma et al., 2007; Hallauer et al., 2010). These results highlight the need to use the testcross' phenotype in mapping studies rather than lines' as done previously (Trachsel et al., 2009, 2010), when aiming to identify QTL to be deployed in hybrids. Only one QTL detected for grain yield in lines was constitutive across treatments. Since there was low correlation of grain yield among lines and hybrids, its usefulness in breeding programs is limited. No QTL for any other trait was detected across treatments, as observed previously (Edmeades et al., 1999). Nevertheless high correlations were found across treatments for anthesis (hybrids and lines) and for PHT (lines).

One constitutive QTL was identified when QTL reported here were compared to results from another study evaluating the same population under nitrogen deficient conditions (DHpop1; Liu personal communication) and an advanced backcross population with a common parent (LPSC7F64; Trachsel et al., 2016) under DS and WW. A senescence QTL under drought (Trachsel et al., 2016) and nitrogen deficient conditions (Liu personal communication) was also detected in bin 4.05; only for linesDS here, for two populations of hybrids under low $\mathrm{N}$ stress (Liu personal communication). These findings are in agreement with two QTL related to senescence detected in this bin by Belícuas et al. (2014) under rain-fed conditions. This QTL has great value for breeding as it could bring yield advantages under two common stresses occurring in tropics (i.e., drought and low soil nitrogen) through improved stay-green. Two candidate genes related to senescence have been reported in this bin. One is SWEET15a, which regulates sucrose translocation in the plant (Chen, 2014). The second is nnrl, which regulates nitrate reductase, a crucial enzyme in nitrite assimilation in plants (Rockel et al., 2002).

\section{Correlation Between Genomic Prediction Accuracy and Trait Heritability}

In this study, the results showed that the prediction accuracy of grain yield under WW conditions was better than that under DS conditions. The prediction accuracy of the secondary traits were generally higher than the prediction accuracy of GY under almost all the conditions. However, a positive correlation was only observed between the genomic prediction accuracy and trait heritability for hybrids WW. Low correlation between genomic prediction accuracy and trait heritability was observed for all other treatment-by-population combinations. Since the training population was of the same size for all traits the lower prediction accuracy irrespective of the heritability could potentially be attributed to reduced phenotypic variation or large genotype-byenvironment interaction (Zhang et al., 2017). Since Combs and Bernardo (2013) additionally show that prediction accuracy may also be dependent on the genetic architecture of a specific trait it is conceivable that genetic and physiological mechanisms acting under stressed conditions are responsible for the observed lack of correlation between trait heritability and prediction accuracy.

\section{$R^{2}$ of QTL and Prediction Accuracy of GS Models for Grain Yield and Secondary Traits}

Prediction accuracy of GS-MAS was higher than the overall variance explained by all QTL for a trait $\left(\mathrm{R}^{2}\right)$ in QTL-MAS for grain yield as observed previously (Meuwissen et al., 2001; Bernardo and Yu, 2007; Lorenzana and Bernardo, 2009; Mayor and Bernardo, 2009; Heffner et al., 2010; Guo et al., 2012; Zhao et al., 2012). A similar pattern was observed for secondary traits (i.e., anthesis, PHT, ASI, NDVI, senescence, leaf rolling and GLAD). From a practical point of view, strong QTL remain important in QTL-MAS, as suggested by Heffner et al. (2010). While GS-MAS requires several hundred markers, only flanking markers of target QTL are needed in QTL-MAS. Detected QTL with beneficial effects on early vigor, drought escape, grain yield and stay-green, such as the ones detected in bins 1.02, 1.03, 7.04, and 4.05 could be used in forward breeding to enrich alleles for these traits in a breeding program or for line conversions, while GS-MAS could be used in more mature breeding programs to additionally capture alleles with smaller additive effects (Heffner et al., 2010; Cao et al., 2017). Ideally selection could be carried out for major and minor additive effects simultaneously by using major QTLs as fixed factors in GS-MAS as described by Bernardo (2014).

\section{Best Performing Hybrids}

To be commercially successful, a hybrid needs to perform well under non-stressed and stressed conditions. The fact that no hybrid reached the top ten under both WW and DS conditions is indicative of the difficulty to achieve high grain yield across environmental conditions due to potential physiological tradeoffs between optimal and stressed conditions. However, hybrids (LPSC7F64/CML495)DH220/CML494, (LPSC7F64/CML495)DH290/CML494 and (LPSC7F64/CML495)DH30/CML494 performed well under WW conditions (all of them in the top ten) and drought stressed conditions (all of them were within the best 22 out of 190). Their superior yield potential and stability was reflected by $12 \%$ higher grain yield relative to the commercial check (DK357) under both WW and DS conditions. Also, the hybrid (LPSC7F64/CML495)DH109/CML494, ranking 14th and 27th out of 190 under WW and DS conditions, respectively (data not shown) ranked fourth in a study where the same set of hybrids was grown under low nitrogen (Liu et al., personal communication). After further evaluations across sites, in combination with multiple testers, lines DH220, DH290 and DH30 could be released as CIMMYT maize lines for deployment in drought prone environments, while line DH190 could potentially be used in environments prone to drought and low nitrogen.

\section{AUTHOR CONTRIBUTIONS}

ST and RB designed and conceived the experiment; CM, ES, and ST carried out the experiments; DC, YY, SC, XZ, and ST analyzed the data; DC and ST wrote the manuscript. 


\section{ACKNOWLEDGMENTS}

We would like to thank the CGIAR research program on climate change, agriculture and food security (CCAFS) for the financial support of this study and MasAgro project funded by Mexico's Secretariat of Agriculture, Livestock, Rural Development, Fisheries, and Food (SAGARPA) providing

\section{REFERENCES}

Almeida, G. D., Makumbi, D., Magorokosho, C., Nair, S., Borém, A., and Ribaut, J. M. (2013). QTL mapping in three tropical maize populations reveals a set of constitutive and adaptive genomic regions for drought tolerance. Theor. Appl. Genet 126, 583-600. doi: 10.1007/s00122-012-2003-7

Bartels, D., and Sunkar, R. (2005). Drought and salt tolerance in plants. Crit. Rev. Plant Sci. 24, 23-58. doi: 10.1080/07352680590910410

Belícuas, P. R., Aguiar, A. M., Bento, D. A. V., Câmara, T. M. M., and de Souza Junior, C. L. (2014). Inheritance of the stay-green trait in tropical maize. Euphytica 198, 163-173. doi: 10.1007/s10681-014-1106-4

Bernardo, R. (2014). Genomide selection when major genes are known. Crop Sci. 54, 68-75. doi: 10.2135/cropsci2013.05.0315

Bernardo, R., and $\mathrm{Yu}, \mathrm{J}$. (2007). Genome wide selection for quantitative traits in maize. Crop Sci. 47, 1082-1090. doi: 10.2135/cropsci2006. 11.0690

Bernier, G., Atlin, G. N., Serraj, R., Kumar, A., and Spaner, D. (2008). Breeding upland rice for drought resistance. J. Sci. Food Agric. 88, 927-939. doi: 10.1002/jsfa.3153

Betrán, F. J., Beck, D., Bänziger, M., and Edmeades, G. O. (2003). Secondary traits in parental inbreds and hybrids under stress and non-stress environments in tropical maize. Field Crop Res. 83, 51-65. doi: 10.1016/S0378-4290(03)00061-3

Beyene, Y., Semagn, K., Crossa, J., Mugo, S., Atlin, G. N., and Tarekegne, A. (2016). Improving maize grain yield under drought stress and non-stress environments in sub-Saharan Africa using marker-assisted recurrent selection. Crop Sci. 56, 344-353. doi: 10.2135/cropsci2015.02.0135

Bolanos, J., and Edmeades, G. O. (1996). The importance of the anthesis-silking interval in breeding for drought tolerance in tropical maize. Field Crop Res. 48, 65-80. doi: 10.1016/0378-4290(96)00036-6

Bommert, P., Goldshmidt, A., and Jackson, D. (2013). The maize G $\alpha$ gene COMPACT PLANT2 functions in CLAVATA signaling to control shoot meristem size. Nature 502, 555-558. doi: 10.1038/nature12583

Cai, H., Chen, F., Mi, G., Zhang, F., Maurer, H. P., and Liu, W. (2012). Mapping QTLs for root system architecture of maize (Zea mays L.) in the field at different developmental stages. Theor. Appl. Genet. 12, 1313-1324. doi: 10.1007/s00122-012-1915-6

Cairns, J. E., Crossa, J., Zaidi, P. H., Grudloyma, P., Sanchez, C., and Araus, J. L. (2013). Identification of drought, heat, and combined drought and heat tolerant donors in maize. Crop Sci 53, 1335-1346. doi: 10.2135/cropsci2012.09.0545

Cao, S., Loladze, A., Yuan, Y., Wu, Y., Zhang, A., Chen, J., et al. (2017). GenomeWide Analysis of Tar Spot Complex Resistance in Maize Using Genotypingby-Sequencing SNPs and Whole-Genome Prediction. Plant Genome. 10, doi: 10.3835/plantgenome2016.10.0099

Chapman, S. C., and Edmeades, G. O. (1999). Selection improves drought tolerance in tropical maize populations. II. Direct and correlated responses among secondary traits. Crop Sci. 39, 1315-1324. doi: $10.2135 /$ cropsci1999.3951315x

Chen, L. Q. (2014). SWEET sugar transporters for phloem transport and pathogen nutrition. New Phytol. 201, 1150-1155. doi: 10.1111/nph. 12445

CIMMYT (2005). Laboratory Protocols: CIMMYT Applied Molecular Genetics Laboratory, 3rd Edn. Mexico, DF: CIMMYT.

Combs, E., and Bernardo, R. (2013). Accuracy of genomewide selection for different traits with constant population size, heritability, and number of markers. Plant Gen. 6, 1-7. doi: 10.3835/plantgenome2012.11.0030

Cooper, M., and Delacy, I. H. (1994). Relationships among analytical methods used to study genotypic variation and genotype-by-environment interaction in plant financial support to DC. Furthermore, we would like to thank Oscar Banuelos, Oscar Garcia, Felipe Espinoza, Simon Pastrana, Sotero Rivas, Doroteo Rivera, and Aristeo Vazquez for technical assistance with the trials; Noel Gomez for hosting us at the experimental station of INIFAP in Iguala. We would also like to thank the CGIAR research program for MAIZE for the financial contribution for the publication of this manuscript.

breeding multi-environment experiments. Theor. Appl. Genet. 88, 561-572. doi: 10.1007/BF01240919

Echt, C. S., Polaeeo, M. L., and Neuffer, M. G. (1987). A nuclear encoded chloroplast ATP synthase mutant of Zea mays L. Mol. Gen. Genet. 208, 230-234. doi: $10.1007 / \mathrm{BF} 00330447$

Edmeades, G. O., Bola-os, J., Chapman, S. C., Lafitte, H. R., and Banziger, M. (1999). Selection improves drought tolerance in tropical maize populations: I. Gains in biomass, grain yield, and harvest index. Crop Sci. 39, 1306-1315. doi: $10.2135 /$ cropsci1999.3951306x

Elshire, R. J., Glaubitz, J. C., Sun, Q., Poland, J. A., Kawamoto, K., and Buckler, E. S. (2011). A robust, simple genotyping-by-sequencing (GBS). Approach High Div. Species 6, 1-10. doi: 10.1371/journal.pone.0019379

Endelman, J. B. (2011). Ridge regression and other kernels for genomic selection with $\mathrm{R}$ package rrBLUP. Plant Genome 4, 250-255. doi: 10.3835/plantgenome2011.08.0024

Grieder, C., Trachsel, S., and Hund, A. (2013). Early vertical distribution of roots and its association with drought tolerance in tropical maize. Plant Soil 377, 295-308. doi: 10.1007/s11104-013-1997-1

Guo, Z., Tucker, D. M., Lu, J., Kishore, V. and Gay, G. (2012). Evaluation of genome-wide selection efficiency in maize nested association mapping populations. Theor. Appl. Genet. 124, 261-275. doi: 10.1007/s00122-011-1702-9

Guo, Z., Tucker, D. M., Wang, D., Basten, C. J., Ersoz, E., Briggs, W. H., et al. (2013). Accuracy of across-environment genome-wide prediction in maize nested association mapping populations. G3 (Bethesda) 3, 263-272. doi: $10.1534 / \mathrm{g} 3.112 .005066$

Hallauer, A. R., Carena, M. J., and Miranda Filho, J. F. (2010). Quantitative Genetics in Maize Breeding, Vol. 663. Iowa State University Press.

Hammer, G. L., Dong, Z., McLean, G., Doherty, A., Messina, C., and Schussler, J. (2009). Can changes in canopy and/or root system architecture explain historical maize yield trends in the U.S. corn belt? Crop Sci. 49, 299-312. doi: 10.2135/cropsci2008.03.0152

Hao, Z., Li, X., and Liu, X. (2010). Meta-analysis of constitutive and adaptive QTL for drought tolerance in maize. Euphytica 174, 165-177. doi: 10.1007/s10681-009-0091-5

Heffner, E. L., Lorenz, A. J., Jannink, J. L., and Sorrells, M. E. (2010). Plant breeding with genomic selection: gain per unit time and cost. Crop Sci. 50, 1681-1690. doi: $10.2135 /$ cropsci2009.11.0662

Heisey, P. W., and Edmeades, G. O. (1999). World Maize Facts and Trends 1997/98 Maize Production in Drought-Stressed Environments: Technical Options and Research Resource Allocation. Agricultural Economics, Vol. 74. Mexico City: CIMMYT.

Jonas, E., and De Koning, J. D. (2016). Goals and Hurdles for a Successful Implementation of Genomic Selection in Breeding Programme for Selected Annual and Perennial Crops. Crops Biotechnol Genet. Eng. Rev. 32, 18-42. doi: 10.1080/02648725.2016.1177377

Li, Y., Ye, W., Wang, M., and Yan, X. (2009). Climate change and drought: a risk assessment of crop-yield impacts. Clim. Res. 39, 31-46. doi: 10.3354/cr00797

Lobell, D. B., Bänziger, M., Magorokosho, C., and Vivek, B. (2011). Nonlinear heat effects on African Maize as evidenced by historical yield trials. Nature Climate Change 1, 42-45. doi: 10.1038/nclimate1043

Lorenzana, R. E., and Bernardo, R. (2009). Accuracy of genotypic value predictions for marker-based selection in biparental plant populations. Theor. Appl. Genet. 120, 151-161. doi: 10.1007/s00122-009-1166-3

Mayor, P. J., and Bernardo, R. (2009). Genome wide selection and marker-assisted recurrent selection in doubled haploid versus F2 populations. Crop Sci. 49, 1719-1725. doi: 10.2135/cropsci2008.10.0587 
Mei, H. W., Li, Z. K., Shu, Q. Y., Guo, L. B., Wang, Y. P., and Yu, X. Q. (2005). Gene actions of QTLs affecting several agronomic traits resolved in a recombinant inbred rice population and two backcross populations. Theor. Appl. Genet. 110, 649-659. doi: 10.1007/s00122-004-1890-7

Messmer, R., Fracheboud, Y., Bänziger, M., Stamp, P., and Ribaut, J. M. (2011). Drought stress and tropical maize: QTLs for leaf greenness, plant senescence, and root capacitance. Field Crop Res. 124, 93-103. doi: 10.1016/j.fcr.2011.06.010

Messmer, R., Fracheboud, Y., Bänziger, M., Vargas, M., Stamp, P., and Ribaut, J. M. (2009). Drought stress and tropical maize: QTL-by-environment interactions and stability of QTLs across environments for yield components and secondary traits. Theor. Appl. Genet. 119, 913-930. doi: 10.1007/s00122-009-1099-x

Meuwissen, T. H. E., Hayes, B. J., and Goddard, M. E. (2001). Prediction of total genetic value using genome-wide dense marker maps. Genetics 157, 1819-1829.

Mihaljevic, R., Utz, H. F., and Melchinger, A. E. (2005). No evidence for epistasis in hybrid and per se performance of elite European flint maize inbreds from generation means and QTL analyses. Crop Sci. 45, 2605-2613. doi: $10.2135 /$ cropsci2004.0760

Monneveux, P., Sánchez, C., Beck, D., and Edmeades, G. O. (2006). Drought tolerance improvement in tropical maize source populations. Crop Sci. 46, 180-191. doi: 10.2135/cropsci2005.04-0034

Nakaya, A., and Isobe, S. N. (2012). Will genomic selection be a practical method for plant breeding? 1303-16. Ann. Bot. 110, 1303-1316. doi: $10.1093 / \mathrm{aob} / \mathrm{mcs} 109$

Peng, T., Sin, X., and Mumm, R. H. (2014). Optimized breeding strategies for multiple trait integration: II. Process efficiency in event pyramiding and trait fixation. Mol. Breed. 33, 105-115. doi: 10.1007/s11032-013-9937-6

Pennisi, E. (2008). The blue revolution, drop by drop, gene by gene. Science 320, 171-173. doi: 10.1126/science.320.5873.171

Poland, J. A., Brown, P. J., Sorrells, M. E., and Jannink, J. (2012). Development of high-density genetic maps for barley and wheat using a novel twoenzyme genotyping-by-sequencing approach. PLoS ONE 7:e32253. doi: 10.1371 /journal.pone.0032253

Porter, J. R., Xie, L., Challinor, A. J., Cochrane, K., Howden, S. M., and Iqbal, M. M. (2014). Food Security and Food Production Systems. Climate Change 2014 - Impacts, Adaptation and Vulnerability: Part A: Global and Sectoral Aspects Working Group II Contribution to the IPCC Fifth Assessment Report, 485-533.

Ray, D. K., Mueller, N. D., West, P. C., and Foley, J. A. (2013). Yield trends are insufficient to double global crop production by 2050. PLOS ONE 8:e66428. doi: 10.1371/journal.pone.0066428

Ribaut, J. M., and Ragot, M. (2007). Marker-assisted selection to improve drought adaptation in maize: the backcross approach, perspectives, limitations, and alternatives. J. Exp. Bot. 58, 351-360. doi: 10.1093/jxb/erl214

Richner, W., Soldati, A., and Stamp, P. (1996). Shoot-to-root relations in field-grown maize seedlings. Agron. J. 88, 56-61. doi: 10.2134/agronj1996.00021962008800010012x

Rockel, P., Strube, F., Rockel, A., Wild, T. J., and Kaiser, W. M. (2002). Regulation of nitric oxide (NO) production by plant nitrate reductase in vivo and in vitro. J. Exp. Bot. 53, 103-110. doi: 10.1093/jexbot/53.366.103

Rong, J., Feltus, F. A., Waghmare, V. N., Pierce, G. J., Chee, P. W., and Draye, X. (2007). Meta-analysis of polyploid cotton QTL shows unequal contributions of subgenomes to a complex network of genes and gene clusters implicated in lint fiber development. Genetics 176, 2577-2588. doi: 10.1534/genetics.107.074518

Rosenzweig, C., Elliott, J., Deryng, D., Ruane, A. C., Müller, C., and Arneth, A. (2014). Assessing agricultural risks of climate change in the 21 st century in a global gridded crop model intercomparison. Proc. Natl. Acad Sci. U.S.A. 111, 3268-3273. doi: 10.1073/pnas. 1222463110

Salvi, S., Corneti, S., Bellotti, M., Carraro, N., Sanguineti, M. C., and Castelletti, S. (2011). Genetic dissection of maize phenology using an intraspecific introgression library. BMC Plant Biol. 11, 4-19. doi: 10.1186/1471-2229-11-4
Schön, C. C., Lee, M., Melchinger, A. E., Guthrie, W. D., and Woodman, W. L. (1993). Mapping and characterization of quantitative trait loci affecting resistance against second-generation European corn borer in maize with the aid of RFLPs. Heredity (Edinb) 70, 648-659. doi: 10.1038/hdy. 1993.93

Sibov, S. T., De Souza, C. L., Garcia, A. A. F., Silva, A. R., Garcia, A. F., and Mangolin, C. A. (2003). Molecular mapping in tropical maize (Zea mays L.) using microsatellite markers. 2. Quantitative trait loci (QTL) for grain yield, plant height, ear height and grain moisture. Hereditas 139, 107-115. doi: $10.1111 /$ j.1601-5223.2003.01667.x

Szalma, S. J., Hostert, B. M., LeDeaux, J. R., Stuber, C. W., and Holland, J. B. (2007). QTL mapping with near-isogenic lines in maize. Theor. Appl. Genet. 114, 1211-1228. doi: 10.1007/s00122-007-0512-6

Trachsel, S., Messmer, R., Stamp, P., and Hund, A. (2009). Mapping of QTLs for lateral and axile root growth of tropical maize. Theor. Appl. Genet. 119, 1413-1424. doi: 10.1007/s00122-009-1144-9

Trachsel, S., Stamp, P., and Hund, A. (2010). Effect of high temperatures, drought and aluminum toxicity on root growth of tropical maize (Zea mays L.) seedlings. Maydica 55, 249-260.

Trachsel, S., Sun, D., San Vicente, F. M., Zheng, H., Atlin, G. N., and Suarez, E. A. (2016). Identification of QTL for early vigor and staygreen conferring tolerance to drought in two connected advanced backcross populations in tropical maize (Zea mays L.). PLoS ONE 11:e0149636. doi: 10.1371/journal.pone.0149636

Tuberosa, R., and Salvi, S. (2009). "QTL for agronomic traits in maize production," in Handbook of Maize: Its Biology, eds, J. L. Bennetzen and S. C. Hake (New York, NY: Springer).

Tuberosa, R., Salvi, S., and Sanguineti, M. C. (2002). Mapping QTLs regulating morpho-physiological traits and yield: case studies, shortcomings and perspectives in drought-stressed maize. Ann. Bot. 89, 941-963. doi: $10.1093 / \mathrm{aob} / \mathrm{mcf134}$

Tuberosa, R., Salvi, S., Sanguineti, M. C., Maccaferri, M., Giuliani, S., and Landi, P. (2003). Searching for quantitative trait loci controlling root traits in maize: A critical appraisal. Plant Soil 255, 35-54. doi: 10.1023/A:1026146615248

Wang, J. K., Li, H. H., Zhang, L. Y., Li, C. H., and Meng, L. (2014). Users' Manual of QTL IciMapping. Beijing. Avaiable online at: http://www.isbreeding. net/software/?type=detail\&id $=14520$

Wu, Y., San Vicente, F., Huang, K., Dhliwayo, T., Costich, D. E., Semagn, K., et al. (2016). Molecular characterization of CIMMYT maize inbred lines with genotyping-by-sequencing SNPs. Theor. Appl. Genet. 129, 753-765. doi: 10.1007/s00122-016-2664-8

Zhang, A., Wang, H., Beyene, Y., Semagn, K., Liu, Y., Cao, S., et al. (2017). Effect of trait heritability, training population size and marker density on genomic prediction accuracy estimation in 22 bi-parental tropical maize populations. Front. Plant Sci. 8:1916. doi: 10.3389/fpls.2017.01916

Zhao, Y., Gowda, M., Liu, W., Würschum, T., Maurer, H., and Longin, F. (2012). Accuracy of genomic selection in european maize elite breeding populations. Theor. Appl. Genet. 124, 769-776. doi: 10.1007/s00122-011-1745-y

Conflict of Interest Statement: The authors declare that the research was conducted in the absence of any commercial or financial relationships that could be construed as a potential conflict of interest.

Copyright (c) 2018 Cerrudo, Cao, Yuan, Martinez, Suarez, Babu, Zhang and Trachsel. This is an open-access article distributed under the terms of the Creative Commons Attribution License (CC BY). The use, distribution or reproduction in other forums is permitted, provided the original author(s) and the copyright owner are credited and that the original publication in this journal is cited, in accordance with accepted academic practice. No use, distribution or reproduction is permitted which does not comply with these terms. 